Check for updates

Cite this: RSC Adv., 2017, 7, 42398

\title{
Enhanced photocatalytic activity of BiOl under visible light irradiation by the modification of $\mathrm{MoS}_{2}$
}

\begin{abstract}
Yuzhen Bu, Junli Xu, (D)* Yawen Li, Qian Liu and Xia Zhang (D)
3D hierarchical $\mathrm{BiOI}$ nanostructures modified with $\mathrm{MoS}_{2}$ were successfully fabricated through a simple

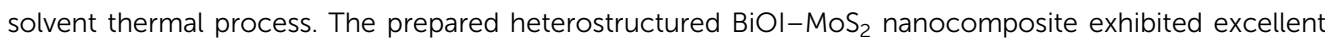
photocatalytic performance in the degradation of methyl orange under visible light irradiation. The photocatalytic activity of $\mathrm{BiOl}-\mathrm{MoS}_{2}$ increases with the increase of $\mathrm{MoS}_{2}$ content first, then it decreases when $\mathrm{MoS}_{2}$ content is over $0.5 \mathrm{wt} \%$. The degradation efficiency of methyl orange could achieve $95 \%$ within $90 \mathrm{~min}$ in the presence of $\mathrm{BiOl}-0.5 \mathrm{wt} \% \mathrm{MoS}_{2}$, which is about two times higher than that of pristine $\mathrm{BiOl}$ nanostructures. The obviously improved photocatalytic performance of $\mathrm{BiOl}-\mathrm{MoS}_{2} \mathrm{Could}$ be mainly attributed to the significantly enhanced separation efficiency of photogenerated charge carriers. However, too much $\mathrm{MoS}_{2}$ loading on the surface of BiOl will prevent light from reaching surface of $\mathrm{BiOl}$ and limit the efficiency of charge separation. Based on active species trapping experiments, holes $\left(\mathrm{h}^{+}\right)$were proved to be the main reactive species in the prepared BiOl-MoS $\mathrm{S}_{2}$ system.
\end{abstract}

Received 9th June 2017

Accepted 26th August 2017

DOI: $10.1039 / \mathrm{c} 7 \mathrm{ra0} 6462 \mathrm{~d}$

rsc.li/rsc-advances

$\mathrm{AgI} / \mathrm{BiOI}-\mathrm{Bi}_{2} \mathrm{O}_{3},{ }^{24} \mathrm{BiOI} / \mathrm{Bi}_{2} \mathrm{WO}_{6},{ }^{25} \mathrm{BiOI} / \mathrm{Ag}_{3} \mathrm{PO}_{4},{ }^{26} \mathrm{BiOI} / \mathrm{Bi}_{2} \mathrm{MoO}_{6},{ }^{27}$ $\mathrm{BiOI} / \mathrm{ZnSn}(\mathrm{OH})_{6}{ }^{28} \mathrm{BiOI} / \mathrm{BiOBr} .{ }^{29}$

$\mathrm{MoS}_{2}$ has a sandwich interlayer structure composed of three stacked atom layers (S-Mo-S) which are bonded together by weak van der Waals forces. ${ }^{30}$ The monolayer $\mathrm{MoS}_{2}$ has been successfully synthesized, and get particular attention in photovoltaic application due to its distinctive electronic, optical, large surface area and catalytically active sites. ${ }^{31-33}$

In view of the fact that $\mathrm{MoS}_{2}$ and BiOI are similar in structure, it is envisaged that a BiOI/MoS 2 composite can have the merits of $\mathrm{MoS}_{2}$ and BiOI, consequently showing high photocatalytic activity under visible light. However, seldom research has been reported on BiOI/ $\mathrm{MoS}_{2}$ composite photocatalytic performance until now. Recently, 2D structure $\mathrm{BiOI} / \mathrm{MoS}_{2}$ (ref. 34) and 3D hierarchical BiOI/ $\mathrm{MoS}_{2} / \mathrm{AgI}^{35}$ were reported which exhibited good photocatalytic activity towards rhodamine B degradation. The degradation efficiencies of RhB after 50 min were $20 \%, 40 \%$ and $96 \%$ by $3 \mathrm{D}$ hierarchical BiOI, BiOI/AgI and $\mathrm{MoS}_{2} / \mathrm{BiOI} / \mathrm{AgI}$ under simulated solar irradiation, respectively. However, the photocatalytic activity of 3D hierarchical BiOI/ $\mathrm{MoS}_{2}$ under visible light irradiation has not been reported yet. Therefore, 3D hierarchical BiOI/MoS ${ }_{2}$ composite was fabricated by a simple solvent thermal process in this work, and the results show that the asprepared BiOI/ $\mathrm{MoS}_{2}$ composites exhibited an excellent photocatalytic activity for the degradation of methyl orange (MO) in visible light irradiation. The possible photocatalytic mechanism of BiOI/ $\mathrm{MoS}_{2}$ heterostructure to MO degradation is proposed by adding radical scavengers in the photocatalytic system.

College of Science, Northeastern University, Shenyang, 110004, China. E-mail: jlxu@ mail.neu.edu.cn; Fax: +86-24-83684533; Tel: +86-24-83684533 


\section{Experimental methods}

\subsection{Synthesis of $\mathrm{MoS}_{2}$, BiOI and BiOI-MoS ${ }_{2}$ composites}

All chemical reagents were of analytical grade and used without further purification in this study. For the preparation of $\mathrm{MoS}_{2}, 5 \mathrm{mmol} \mathrm{Na}_{2} \mathrm{MoO}_{4}$ and $20 \mathrm{mmol} \mathrm{CS}\left(\mathrm{NH}_{2}\right)_{2}$ were dissolved in deionized water with vigorous stirring for $1 \mathrm{~h}$ at room temperature. Then, the mixture was transferred into a $100 \mathrm{ml}$ Teflon-lined stainless-steel autoclave. The autoclave was kept at $483 \mathrm{~K}$ for $24 \mathrm{~h}$. The sample was obtained by filtration, washed with deionized water and absolute ethanol many times, and then dispersed into absolute ethanol and dried for $12 \mathrm{~h}$ at $323 \mathrm{~K}$.

$\mathrm{BiOI} / \mathrm{MoS}_{2}$ composite were synthesized by an ethylene glycol (EG)-assisted solvothermal method. In a typical synthesis procedure, $2 \mathrm{mmol} \mathrm{Bi}\left(\mathrm{NO}_{3}\right)_{3} \cdot 5 \mathrm{H}_{2} \mathrm{O}$ and $2 \mathrm{mmol} \mathrm{KI}$ was dissolved in $15 \mathrm{ml}$ ethylene glycol under ultrasonication for $20 \mathrm{~min}$ respectively first. Then, the two solutions were mixed and some $\mathrm{MoS}_{2}$ was added to the mixture. The mixture was under vigorous stirring for $15 \mathrm{~min}$, then it was transferred into a100 $\mathrm{ml}$ Teflon-lined stainless-steel autoclave. The autoclave was kept at $433 \mathrm{~K}$ for $12 \mathrm{~h}$. The resultant precipitates were collected, repeatedly washed with deionized water and ethanol, and dried for $12 \mathrm{~h}$ at $333 \mathrm{~K}$. BiOI/MoS $\mathrm{Momposites}_{2}$ were named as BiOI- (wt\% of $\mathrm{MoS}_{2}$ ) $\mathrm{MoS}_{2}$. For comparison, BiOI was also fabricated as the same method without the presence of $\mathrm{MoS}_{2}$.

\subsection{Characterization}

The morphologies of the prepared BiOI, $\mathrm{MoS}_{2}$ and $\mathrm{BiOI}-(0.5 \%)$ $\mathrm{MoS}_{2}$ samples were characterized by a PANalytical B.V. MPDDY2094 X-ray diffractometer (XRD) with $\mathrm{Cu} \mathrm{K} \alpha$ radiation ( $\lambda=1.5406 \AA$ A). Scanning electron microscopy (SEM) pictures and quantitative standard microanalyses were obtained using an energy dispersive X-ray analysis (EDS) with a Zeiss ultra plus FESEM apparatus. UV-vis diffuse reflectance spectrum (DRS) was recorded on a Perkin Elmer Lambda 35 UV-vis spectrophotometer with $\mathrm{BaSO}_{4}$ as a reference, and the scanned range being 200-800 $\mathrm{nm}$ against barium sulfate standard. $\mathrm{N}_{2}$ adsorption-desorption isotherm was conducted on a Micromeritics ASAP-2020-HD88 volumetric gas sorption apparatus using $99.999 \%$ pure $\mathrm{N}_{2}$.

The photoluminescence (PL) measurements were performed on a Hitachi F7000 Fluorescence Spectrophotometer with an excitation wavelength of $325 \mathrm{~nm}$ at room temperature. The photocurrents were performed in $0.5 \mathrm{~mol} \mathrm{l}^{-1} \mathrm{Na}_{2} \mathrm{SO}_{4}$ solution using an electrochemistry workstation (CHI 660, China) with a three-electrode system. The obtained sample was served as the working electrode $(1 \mathrm{mg}$ of the as-prepared sample was dispersed in $0.2 \mathrm{ml}$ of ethanol and $0.2 \mathrm{ml}$ of ethanol mixture to produce a suspension, which was then dip-coated onto an ITO glass electrode). A platinum plate and a saturated $\mathrm{Ag} / \mathrm{AgCl}$ were used as the counter electrode and reference electrode, respectively. A $300 \mathrm{~W}$ Xe lamp with main emission wavelength $420 \mathrm{~nm}$ in the range of $420-780 \mathrm{~nm}$ along with a power of $80 \mathrm{~mW} \mathrm{~cm}^{-2}$ was utilized as the photosource.

\subsection{Photocatalytic activity tests}

The photocatalytic activity tests of the obtained samples were investigated by evaluating in terms of the degradation of methyl orange (MO) solution under the simulated sunlight irradiation. The photochemical reactor contains $40 \mathrm{mg}$ catalysts and $5.0 \times$ $10^{-5} \mathrm{~mol} \mathrm{l}^{-1}$ of $100 \mathrm{ml}$ MO. A $300 \mathrm{~W}$ Xe lamp with main emission wavelength $420 \mathrm{~nm}$ in the range of 420-780 nm along with a power of $20 \mathrm{~mW} \mathrm{~cm} \mathrm{~cm}^{-2}$ (Beijing Science and Technology Co., Ltd. Park Philae), was set inside a cylindrical reactor, and surrounded by a circulating water jacket to cool the lamp and minimize infrared radiation. The methyl orange aqueous solutions with the added catalysts were kept in the dark for some minutes to establish the adsorption equilibrium of the methyl orange for the catalyst before exposure to the simulated sunlight. After exposure to the radiation for different intervals, the UV-vis spectrophotometer (TU-1900, Beijing Purkinje General Instrument Co., Ltd.) was used to determine the solution concentration of methyl orange. The absorbance accuracy is $\pm 0.002 \mathrm{Abs}(0-0.5 \mathrm{Abs})$, and $\pm 0.004 \mathrm{Abs}(0.5-1.0 \mathrm{Abs})$.

\section{Results and discussion}

\subsection{Structure and morphology}

Fig. 1 shows the XRD patterns of prepared $\mathrm{MoS}_{2}$, BiOI and BiOI$\mathrm{MoS}_{2}$ samples. The diffraction peaks of $14.43^{\circ}(002), 33.61^{\circ}$ (100), $39.88^{\circ}(103), 58.87^{\circ}$ (110) can be indexed to $\mathrm{MoS}_{2}$ (JCPDS card no. 01-087-2416), while $24.57^{\circ}(101), 29.55^{\circ}(102), 32.13^{\circ}$

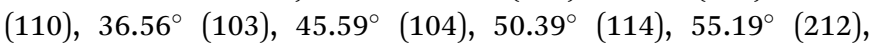
$66.44^{\circ}(214), 75.48^{\circ}$ (310) diffraction peaks are belong to tetragonal phase BiOI (JCPDS card no. 00-010-0445). No peaks of other impurities are observed in the diffraction peaks of the as prepared BiOI and $\mathrm{MoS}_{2}$, indicating that the high purity and single phase of the prepared BiOI and $\mathrm{MoS}_{2}$ products. Moreover, diffraction peaks of $\mathrm{MoS}_{2}$ can be found hardly because of its relatively low content in the prepared BiOI- $\mathrm{MoS}_{2}$ samples.

FESEM images of the $\mathrm{MoS}_{2}$, BiOI and BiOI-0.5\% $\mathrm{MoS}_{2}$ samples are shown in Fig. 2.

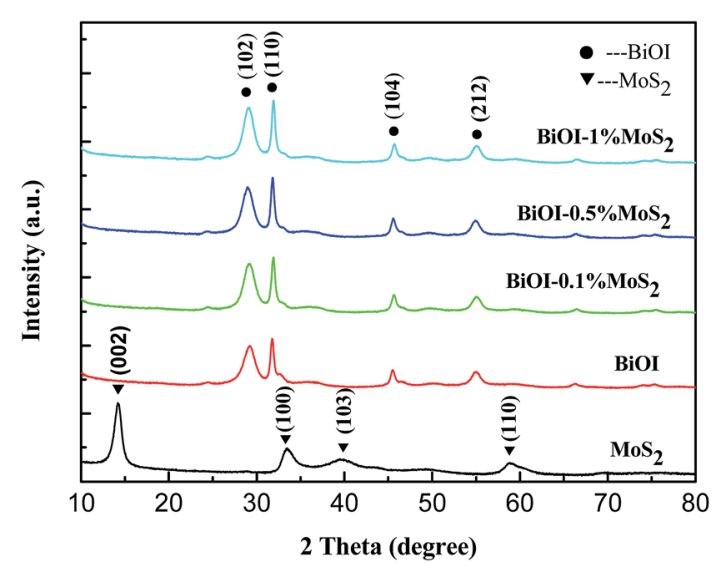

Fig. 1 X-ray diffraction patterns of prepared $\mathrm{MoS}_{2}, \mathrm{BiOl}$ and $\mathrm{BiOl}-$ $\mathrm{MoS}_{2}$ samples. 

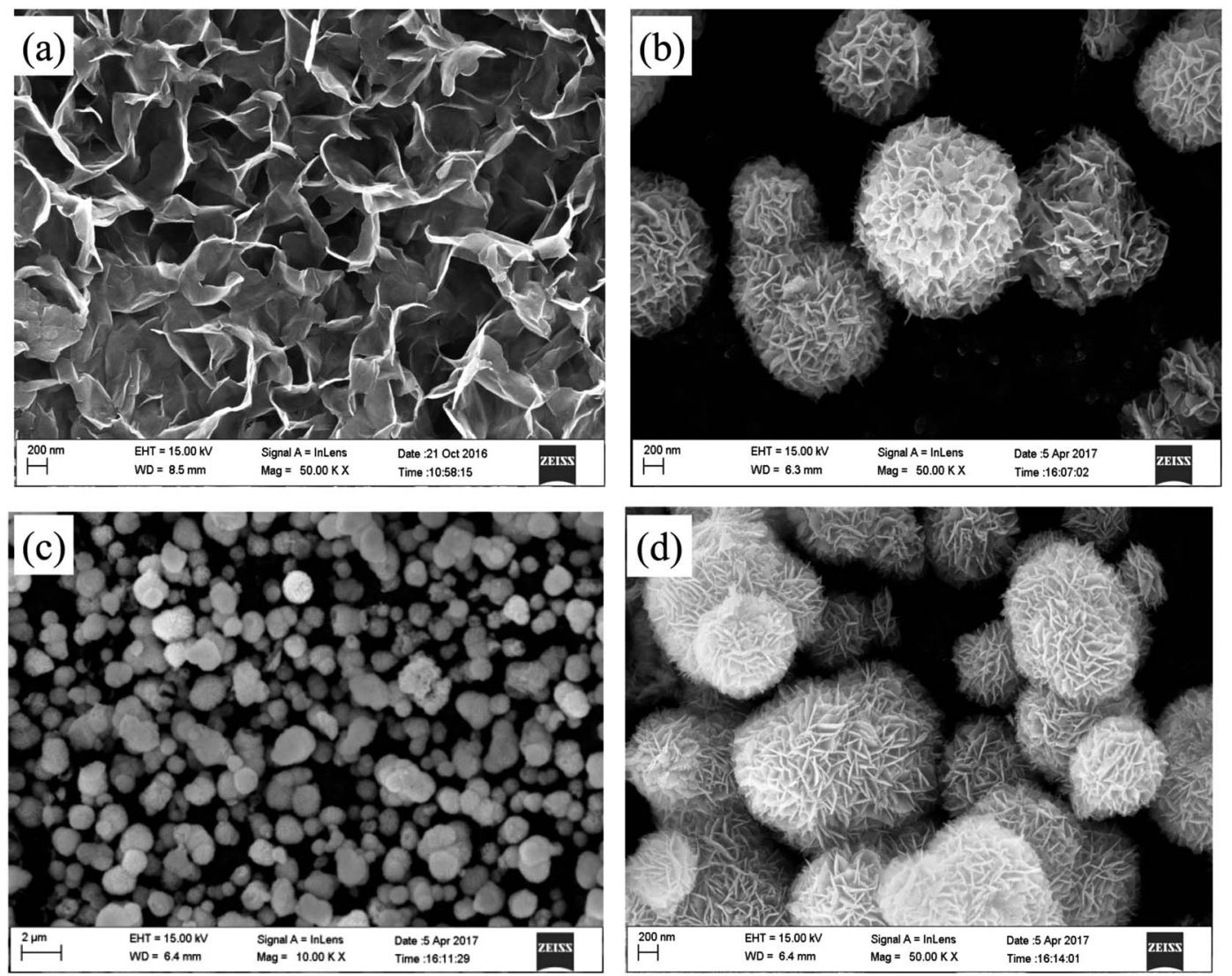

Fig. 2 FESEM images of $\mathrm{MoS}_{2}$ (a), $\mathrm{BiOI}$ (b) and $\mathrm{BiOl}-0.5 \% \mathrm{MoS}_{2}$ (c and d).

As shown in Fig. 2(a), the synthesized $\mathrm{MoS}_{2}$ sample structure is composed of curled and interlaced nanosheets, while BiOI and BiOI-0.5\% $\mathrm{MoS}_{2}$ samples exhibit a similar 3D flower-like hierarchical spherical structure. The flower-like structures have wide size distribution and diameters ranging from approximately $600 \mathrm{~nm}$ to $1.5 \mu \mathrm{m}$. Moreover, these microspheres are not completely isolated from each other, but often coupled together. Compare with pristine BiOI, BiOI-0.5\% $\mathrm{MoS}_{2}$ has smaller spherical size. Close examination of the morphology of reveals that the hierarchical microsphere consisting of loosely stacked nanoplates with an average slide length of about $200 \mathrm{~nm}$. This specific hierarchical nanostructures make the samples have an obvious high surface-to-volume ratio, which is favourable for pollutant molecules transportation and light injection. ${ }^{36,37}$

\subsection{Optical properties}

The optical properties of the samples were investigated by ultraviolet-visible diffuse reflectance spectra and depicted in Fig. 3(a), and the curves of $(\alpha h \nu)^{1 / 2}$ versus $h \nu$ derived from the UV-visible spectra are presented in Fig. 3(b). As shown in Fig. 3(b), the loading of $\mathrm{MoS}_{2}$ can significantly affect the band gap energy compare to pristine BiOI, and the extent of band gap energy greatly depends upon the loading level. The pristine BiOI and $\mathrm{MoS}_{2}$ exhibit a band gap energy of $1.87 \mathrm{eV}$ and $1.71 \mathrm{eV}$ respectively, which is close to the values reported in other literatures. ${ }^{1,38,39}$ Moreover, BiOI- $\mathrm{MoS}_{2}$ composites exhibit larger band gap energy than that of BiOI, as BiOI$\mathrm{MoS}_{2}$ composites exhibit a band gap energy of about $2.25 \mathrm{eV}$ (BiOI-0.1\% $\mathrm{MoS}_{2}$ ), $2.30 \mathrm{eV}$ (BiOI-0.5\% $\mathrm{MoS}_{2}$ ) and $2.25 \mathrm{eV}$ (BiOI-1\% $\mathrm{MoS}_{2}$ ) respectively. Although the addition of $\mathrm{MoS}_{2}$ in BiOI enlarged the band gap of BiOI, the absorbance of BiOI- $\mathrm{MoS}_{2}$ samples are much stronger than that of pristine $\mathrm{BiOI}$ in the visible region, which allows the BiOI- $\mathrm{MoS}_{2}$ catalysts to utilize more visible light during photocatalytic degradation and is expected to enhance the photocatalytic behavior. ${ }^{40}$

\subsection{Adsorption-desorption analysis}

The $\mathrm{N}_{2}$ adsorption-desorption isotherms of the pristine BiOI and BiOI-0.5\% $\mathrm{MoS}_{2}$ samples are shown in Fig. 4 . Both of the isotherms exhibit a typical IV isotherm with a hysteresis loop, suggesting their mesoporous features, which is also confirmed by the corresponding pore size distribution curve (inset in Fig. 4). As shown in Table 1, the BET surface areas were calculated to be 52.87 and $48.81 \mathrm{~m}^{2} \mathrm{~g}^{-1}$ for pristine BiOI and BiOI$0.5 \% \mathrm{MoS}_{2}$ respectively. In addition, the average mesoporous diameter of BiOI- $0.5 \% \mathrm{MoS}_{2}$ is larger than that of pristine BiOI. The BET surface area values did not have obvious difference, which indicates that the BET surface area has little effect on the photocatalytic performance of obtained BiOI and BiOI- $0.5 \%$ $\mathrm{MoS}_{2}$ samples. 

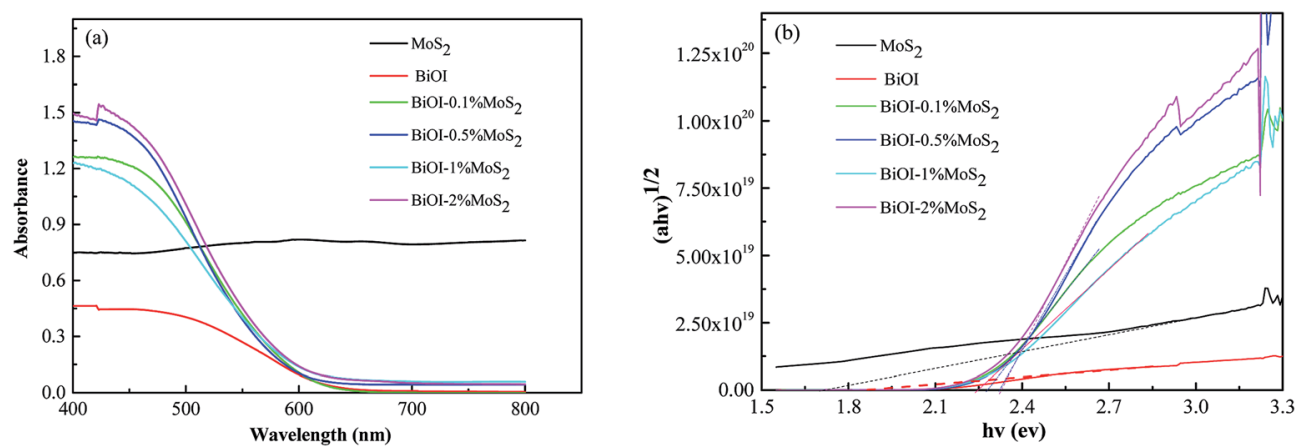

Fig. 3 (a) UV-Vis diffused reflectance spectra of pristine $\mathrm{MoS}_{2}$, BiOl and BiOl-MoS samples; (b) the plots of transformed Kubelka-Munk function versus the energy of light.

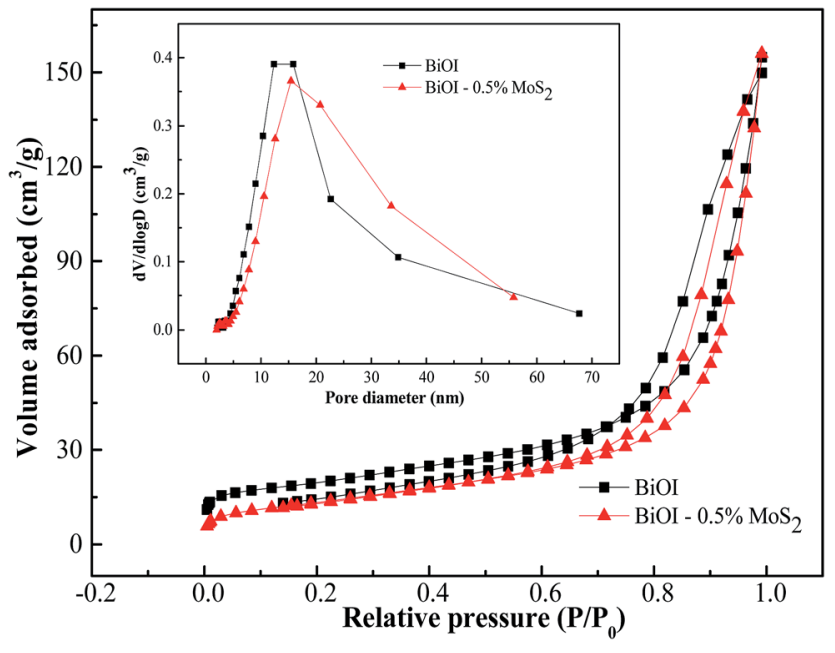

Fig. $4 \quad \mathrm{~N}_{2}$ adsorption and desorption isotherms and the corresponding pore-size distribution (inset) for the $\mathrm{BiOl}$ and $\mathrm{BiOi}-0.5 \% \mathrm{MoS}_{2}$ samples.

Table 1 Textural features of $\mathrm{BiOl}$ and $\mathrm{BiOl}-0.5 \% \mathrm{MoS}_{2}$ samples

\begin{tabular}{llll}
\hline Semiconductor & $\begin{array}{l}\text { BET surface } \\
\text { area }\left(\mathrm{m}^{2} \mathrm{~g}^{-1}\right)\end{array}$ & $\begin{array}{l}\text { Pore volume } \\
\left(\mathrm{cm}^{3} \mathrm{~g}^{-1}\right)\end{array}$ & $\begin{array}{l}\text { Average pore } \\
\text { diameter }(\mathrm{nm})\end{array}$ \\
\hline BiOI & 52.87 & 0.23 & 13.60 \\
BiOI-0.5\% $\mathrm{MoS}_{2}$ & 48.81 & 0.24 & 16.57
\end{tabular}

\subsection{FTIR analysis}

The FTIR spectra of pure BiOI and BiOI-MoS ${ }_{2}$ hybrids are shown in Fig. 5. The peak at around $520 \mathrm{~cm}^{-1}$ is corresponded to the stretching vibration of the $\mathrm{Bi}-\mathrm{O} .{ }^{41}$ Compared with pure BiOI, the stretching vibration of $\mathrm{Bi}-\mathrm{O}$ in $\mathrm{BiOI}-\mathrm{MoS}_{2}$ samples shift to higher frequency region slightly, indicating that there are strong interaction between BiOI and $\operatorname{MoS}_{2}{ }^{34,42}$ The strong interaction between BiOI and $\mathrm{MoS}_{2}$ may be beneficial to the separation of photo-induced charge carriers. In addition, the peak at around $1620 \mathrm{~cm}^{-1}$ is ascribed to the bending vibration absorption of free water molecules, and the broad peak at around $3420 \mathrm{~cm}^{-1}$ is related to the stretching vibrations of $\mathrm{O}-\mathrm{H},{ }^{43,44}$ which could serve as anchor to the contaminant molecules.

\subsection{Photocatalytic performance}

The degradations of methyl orange dye by BiOI- $\mathrm{MoS}_{2}$ samples under visible light irradiation are shown in Fig. 6(a). Error bars in Fig. 6 represent SDs calculated from three parallel experiments. About $50 \% \mathrm{MO}$ was photodegraded by pristine BiOI, and the introduction of $\mathrm{MoS}_{2}$ into BiOI can enhance the degradation efficiency. BiOI-0.5\% $\mathrm{MoS}_{2}$ sample exhibits the best excellent photocatalytic activity towards $\mathrm{MO}$, and the photodegradation rate could reach $95 \%$ under $90 \mathrm{~min}$ of visible light irradiation. Compared to other reported BiOI composites, the prepared BiOI- $\mathrm{MoS}_{2}$ composites shows higher photodegradation properties to MO as shown in Table 2.

The stability is one of the important considerations for the application of a photocatalyst. Recycling experiments on the photocatalytic degradation of methyl orange dye were carried out as shown in Fig. 6(b). The degradation rate is about $80 \%$ for the second and third cycles, while it could maintain at $60 \%$ after four successive cycles. Fig. 7 shows the microstructure of BiOI$0.5 \% \mathrm{MoS}_{2}$ which had gone through four cycles photocatalysis tests. Compared with the microstructure of BiOI- $0.5 \% \mathrm{MoS}_{2}$ before cycles (Fig. 2(c) and (d)), there are more small particles on the surface of spherical BiOI, which indicates the disaggregation of the sponge structure of BiOI. The decrease of the photocatalytic activity may be due to the disaggregation of the sponge structure of BiOI.

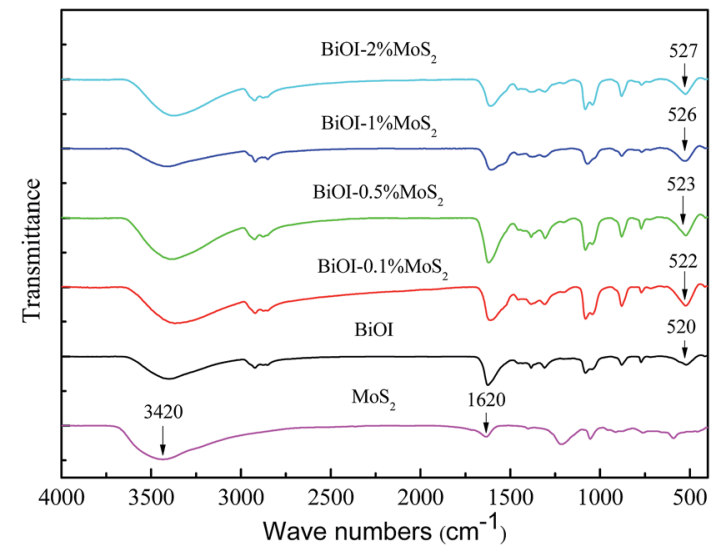

Fig. 5 FTIR spectra of $\mathrm{BiOl}, \mathrm{MoS}_{2}$ and $\mathrm{BiOl}-\mathrm{MoS}_{2}$ samples. 

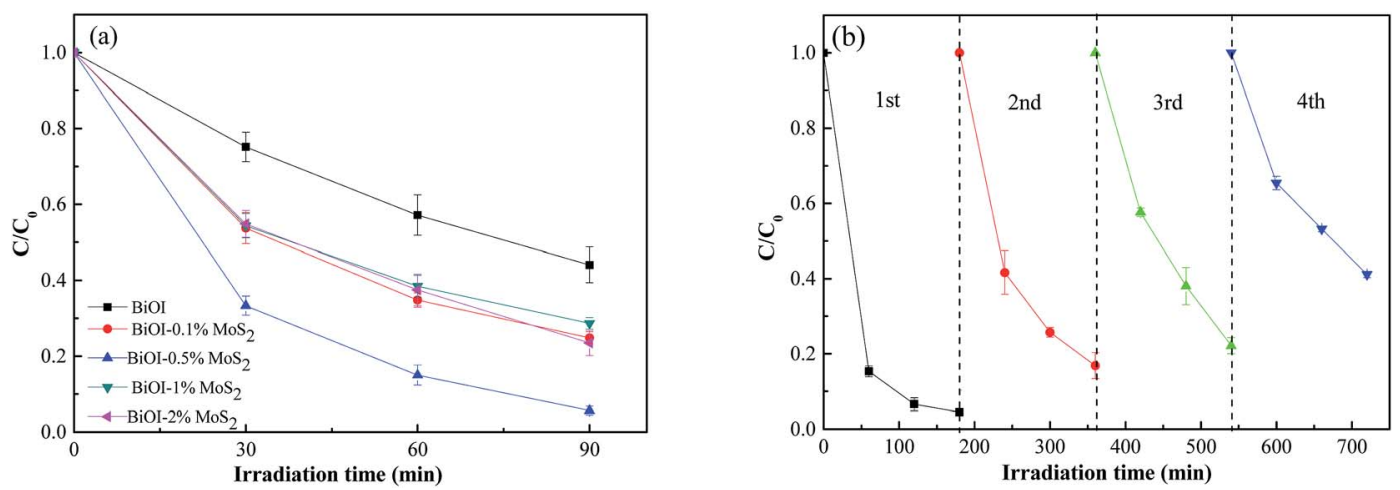

Fig. 6 Degradation properties of $\mathrm{MO}$ by $\mathrm{BiOI}-\mathrm{MoS}_{2}$ samples under visible light irradiation. (a) The relationship between degradation efficiency of $\mathrm{MO}$ and irradiation time. (b) Recycling property of $\mathrm{BiOl}-0.5 \% \mathrm{MoS}_{2}$ in the degradation of $\mathrm{MO}$

Table 2 Photodegradation properties of some reported BiOl based composites to MO solution under visible light irradiation

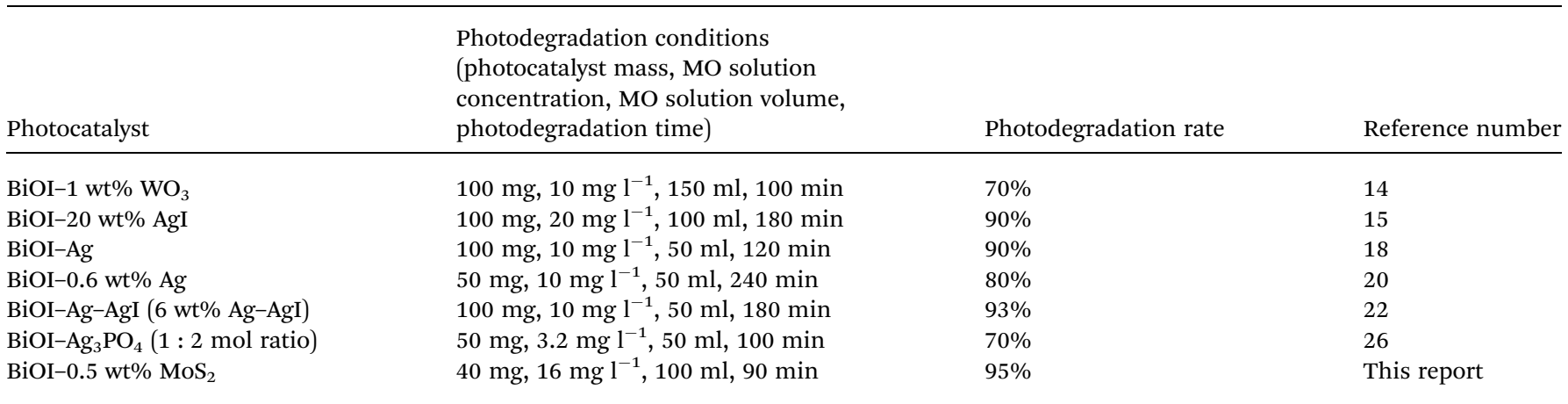

Photoluminescence (PL) spectrum and photocurrent generation are effective techniques to evaluate the efficiency of charge carrier trapping, transfer and separation in semiconductor materials and surface defects of samples. Fig. 8(a) shows the room temperature PL spectra of prepared BiOI and BiOI- $\mathrm{MoS}_{2}$ composites with an excitation wavelength of $325 \mathrm{~nm}$. There are three intense emission peaks centered around $370 \mathrm{~nm}, 590 \mathrm{~nm}$ and $620 \mathrm{~nm}$. The BiOI-0.5\% $\mathrm{MoS}_{2}$ exhibited the lowest peak intensity, while BiOI exhibited the highest peak intensity. This result implies BiOI-0.5\% $\mathrm{MoS}_{2}$ has the lowest rate of recombination of photogenerated charge carriers, while BiOI has the highest rate of recombination of photogenerated charge carriers.

Fig. 8(b) showed the photocurrent response of BiOI, $\mathrm{MoS}_{2}$ and $\mathrm{BiOI}-0.5 \% \mathrm{MoS}_{2}$ with illumination of visible light. The rapid increase photocurrent response from a light-off to lighton state was mainly due to the fast separation and transfer of the photogenerated electrons on the surface of the working electrode. As shown in Fig. 8(b), the photocurrent density generated by BiOI- $0.5 \% \mathrm{MoS}_{2}$ was much higher than that by
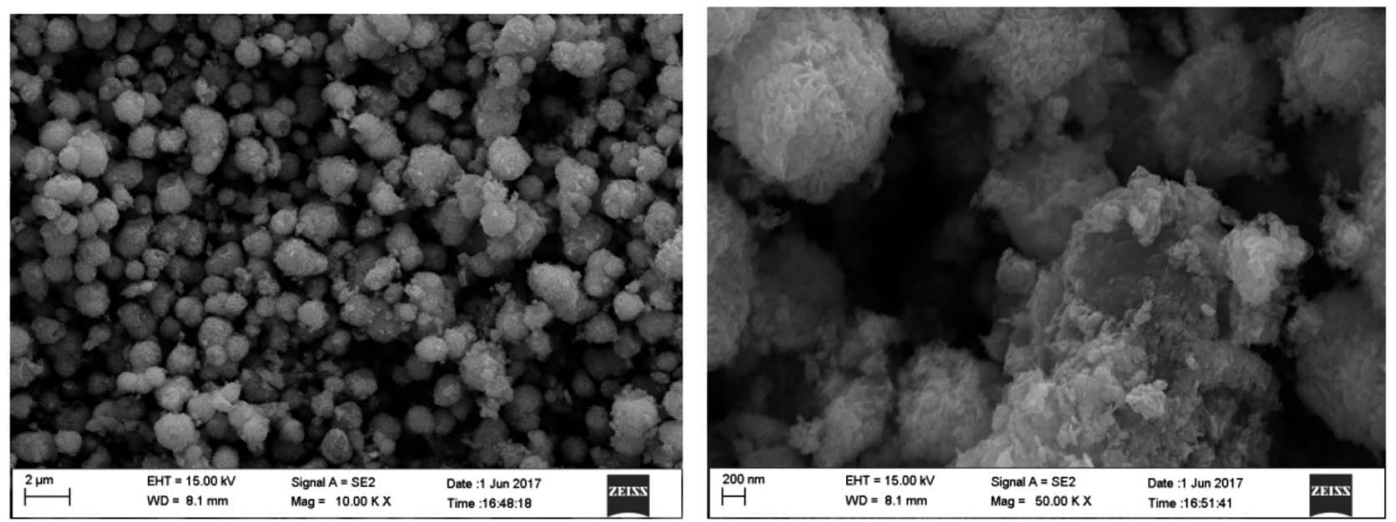

Fig. 7 FESEM images of $\mathrm{BiOl}-0.5 \% \mathrm{MoS}_{2}$ after four photocatalysis cycles. 

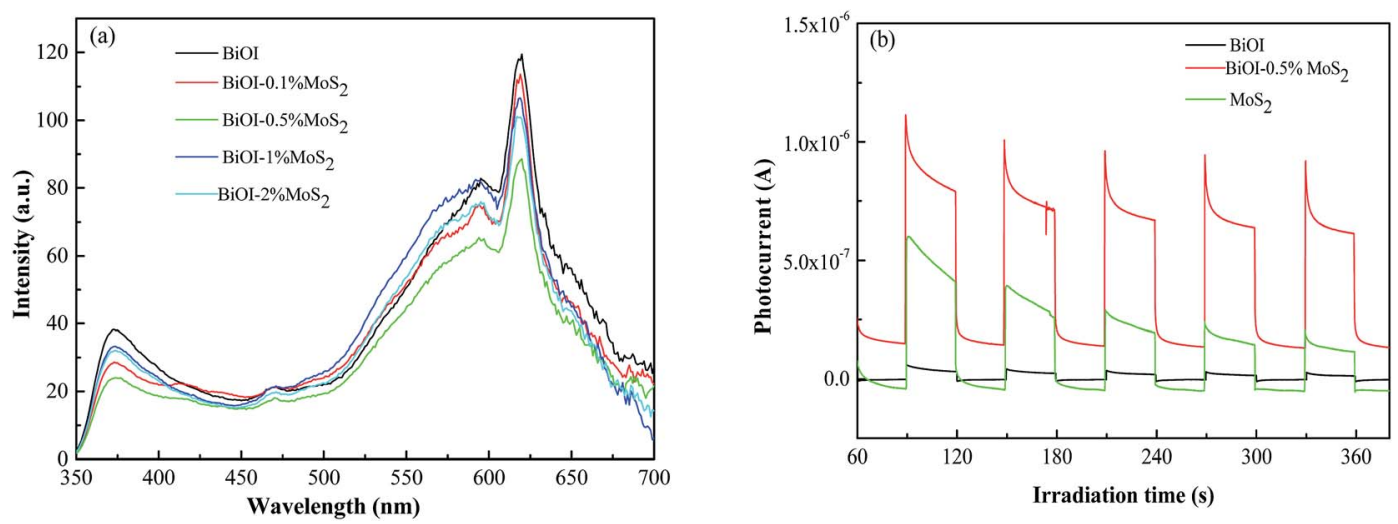

Fig. 8 (a) Photoluminescence spectra of $\mathrm{BiOI}$ and $\mathrm{BiOl}-\mathrm{MoS}_{2}$ composites; (b) transient photocurrent response of $\mathrm{BiOl}, \mathrm{MoS} 2$ and $\mathrm{BiOl}-0.5 \%$ $\mathrm{MoS}_{2}$ under visible light irradiation.

BiOI, which indicate that BiOI-0.5\% $\mathrm{MoS}_{2}$ has more efficiency separation rate of photogenerated carriers than BiOI. This result is consistent with the results of PL, and it could be speculated that the separation of photogenerated carriers may be one of the reasons for the highest photocatalytic performance of BiOI- $0.5 \% \mathrm{MoS}_{2}$ on $\mathrm{MO}$ degradation.

Moreover, the energy of conduction band edge $\left(E_{\mathrm{CB}}\right)$ and the energy of valence band edge $\left(E_{\mathrm{VB}}\right)$ can be calculated by using the following equations: ${ }^{45}$

$$
E_{\mathrm{CB}}=-\chi+0.5 E_{\mathrm{g}}
$$

and

$$
E_{\mathrm{VB}}=-\chi-0.5 E_{\mathrm{g}}
$$

where, $\chi$ is the absolute electronegativity of the semiconductor, and $E_{\mathrm{g}}$ is the band gap energy of the semiconductor. The absolute electronegativity of BiOI and $\mathrm{MoS}_{2}$ is $5.99 \mathrm{eV}$ (ref. 8) and $5.32 \mathrm{eV}$ (ref. 45) respectively. As the pristine BiOI and $\mathrm{MoS}_{2}$ exhibit a band gap energy of $1.87 \mathrm{eV}$ and $1.71 \mathrm{eV}$ respectively as

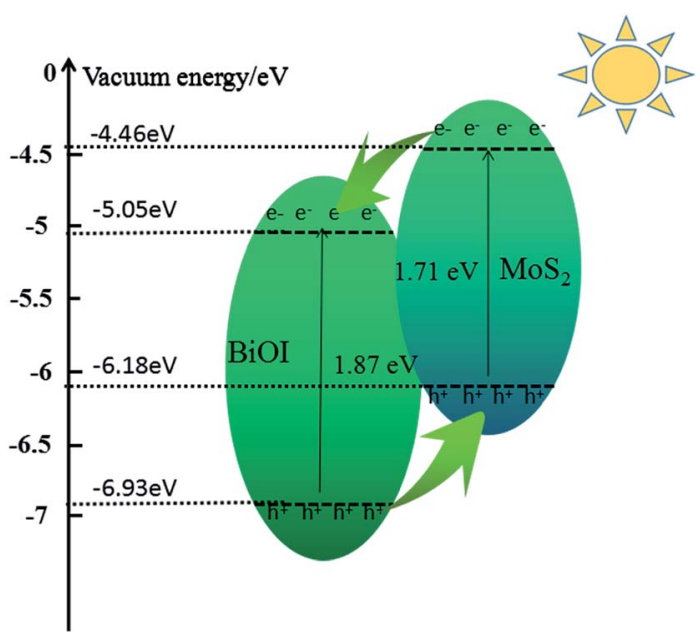

Fig. 9 Schematic diagram illustrating the principle of photo-induced charge transfer in $\mathrm{BiOl}-\mathrm{MoS}_{2}$ semiconductor. shown in Fig. 3(b), the calculated $E_{\mathrm{CB}}$ and $E_{\mathrm{VB}}$ of BiOI is about $-5.05 \mathrm{eV}$ and $-6.93 \mathrm{eV}$, while it is $-4.46 \mathrm{eV}$ and $-6.18 \mathrm{eV}$ for $\mathrm{MoS}_{2}$ respectively. Therefore, it is thermodynamically favorable for the direct electron transfer from the conduction band of $\mathrm{MoS}_{2}$ to the conduction band of BiOI, while the holes transfer from the valance band of BiOI to the valance band of $\mathrm{MoS}_{2}$ as shown in Fig. 9.

\subsection{Photocatalytic mechanism}

To survey the photocatalytic disinfection mechanism, active species trapping experiments were conducted and the results are shown in Fig. 10. Error bars in Fig. 10 represent SDs calculated from three parallel experiments. Ammonium oxalate and isopropanol were chose as $\mathrm{h}^{+}$scavengers and $\mathrm{OH}$ scavengers respectively. As shown in Fig. 10, comparing with the photodegradation efficiency without scavenger, the photodegradation efficiency is decreased obviously when ammonium oxalate was added into the MO solution. However, it is only a little decreased when isopropanol was added into the MO solution. This result indicates that $\mathrm{h}^{+}$was the main reactive

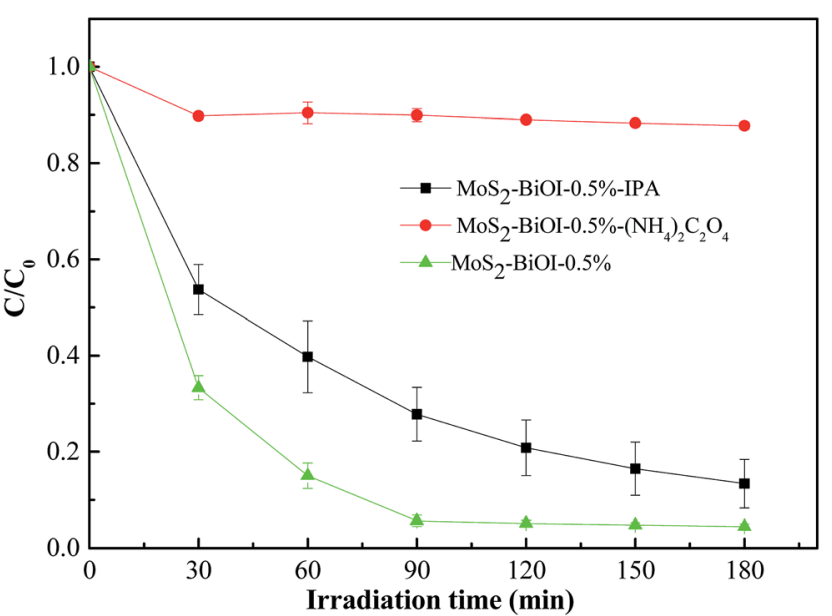

Fig. 10 Scavenger effects on the degradation of MO solution under visible light irradiation. 
species in the photodegradation of MO for the prepared BiOI$\mathrm{MoS}_{2}$ samples under visible light irradiation.

\subsection{Discussion on the effects of $\mathrm{MoS}_{2}$ on the photocatalytic activity}

From Fig. 6, it is deduced that the photocatalytic activity of BiOI increased with the loading of $\mathrm{MoS}_{2}$ on BiOI. The photocatalytic activity of $\mathrm{BiOI}-\mathrm{MoS}_{2}$ increases with the increase of $\mathrm{MoS}_{2}$ contents first, then it decreases when $\mathrm{MoS}_{2}$ content is over $0.5 \mathrm{wt} \%$. This can be attributed to two main reasons. First, it is thermodynamically favorable for the direct electron transfer from the conduction band of $\mathrm{MoS}_{2}$ to the conduction band of BiOI, while the holes transfer from the valance band of BiOI to the valance band of $\mathrm{MoS}_{2}$ as shown in Fig. 9. Thus, the modification of $\mathrm{MoS}_{2}$ on BiOI can accelerate the division and restrain the recombination of photogenerated electron-hole pairs, resulting in the improved photocatalytic activity. Second, too much $\mathrm{MoS}_{2}$ loading on the surface of BiOI will prevent light from reaching surface of BiOI, and thus reduce the generation of electrons and holes. In addition, too much $\mathrm{MoS}_{2}$ loading will also limit the efficiency of charge separation, which is confirmed by the photoluminescence spectra of pure BiOI and BiOI- $\mathrm{MoS}_{2}$ composites as shown in Fig. 8(a).

\section{Conclusions}

3D hierarchical BiOI modified by $\mathrm{MoS}_{2}$ with excellent photocatalytic performance in the degradation of methyl orange under visible light irradiation were successfully fabricated through a simple solvent thermal process. The photocatalytic activity of BiOI- $\mathrm{MoS}_{2}$ for the degradation of methyl orange increases with the increase of $\mathrm{MoS}_{2}$ contents first, then it decreases when $\mathrm{MoS}_{2}$ content is over $0.5 \mathrm{wt} \%$. The degradation efficiency of methyl orange for BiOI-0.5\% $\mathrm{MoS}_{2}$ is about two times higher than that of bare BiOI nanostructures. The enhanced photocatalytic activities could be attributed to higher separation efficiency of photogenerated charge carriers. However, radicals and holes trapping experiments showed that $\mathrm{h}^{+}$dominates the photodegradation process of MO.

\section{Conflicts of interest}

There are no conflicts to declare.

\section{Acknowledgements}

The authors gratefully acknowledge the financial support from the National Natural Science Foundation of China (No. 51574071).

\section{References}

1 X. Zhang, Z. H. Ai, F. L. Jia and L. Z. Zhang, Generalized onepot synthesis, characterization, and photocatalytic activity of hierarchical $\mathrm{BiOX}(\mathrm{X}=\mathrm{Cl}, \mathrm{Br}, \mathrm{I})$ nanoplate microspheres, $J$. Phys. Chem. C, 2008, 112(3), 747-753.
2 X. Y. Qin, H. F. Cheng, W. J. Wang, B. B. Huang, X. Y. Zhang and Y. Dai, Three dimensional $\mathrm{BiOX}(\mathrm{X}=\mathrm{Cl}, \mathrm{Br}$ and $\mathrm{I})$ hierarchical architectures: facile ionic liquid-assisted solvothermal synthesis and photocatalysis towards organic dye degradation, Mater. Lett., 2013, 100(6), 285-288.

3 K. L. Zhang, C. M. Liu, F. Q. Huang, C. Zheng and W. D. Wang, Study of the electronic structure and photocatalytic activity of the BiOCl photocatalyst, Appl. Catal., B, 2006, 68(3-4), 125-129.

4 W. D. Wang, F. Q. Huang, X. P. Lin and J. H. Yang, Visiblelight-responsive photocatalysts xBiOBr-(1-x)BiOI, Catal. Commun., 2008, 9(1), 8-12.

5 J. Cao, B. Y. Xu, B. D. Luo, H. L. Lin and S. F. Chen, Novel $\mathrm{BiOI} / \mathrm{BiOBr}$ heterojunction photocatalysts with enhanced visible light photocatalytic properties, Catal. Commun., 2011, 13(1), 63-68.

6 X. F. Chang, J. Huang, C. Cheng, Q. Sui, W. Sha, G. B. Ji, S. B. Deng and G. Yu, BiOX $(\mathrm{X}=\mathrm{Cl}, \mathrm{Br}, \mathrm{I})$ photocatalysts prepared using $\mathrm{NaBiO}_{3}$, as the Bi source: characterization and catalytic performance, Catal. Commun., 2010, 11(5), 460-464.

7 W. D. Wang, F. Q. Huang and X. Q. Lin, xBiOI-(1-x)BiOCl as efficient visible-light-driven photocatalysts, Scr. Mater., 2007, 56(8), 669-672.

8 Y. G. Li, J. S. Wang, H. C. Yao, L. Y. Dang and Z. J. Li, Efficient decomposition of organic compounds and reaction mechanism with BiOI photocatalyst under visible light irradiation, J. Mol. Catal. A: Chem., 2011, 334(1-2), 116-122.

9 Y. F. Chen, J. H. Fang, S. Y. Lu, Y. Wu, D. Z. Chen, L. Y. Huang, W. C. Xu, X. M. Zhu and Z. Q. Fang, Fabrication characterization and photocatalytic properties of $\mathrm{Ag} / \mathrm{AgI} / \mathrm{BiOI}$ heteronanostructures supported on rectorite via a cation-exchange method, Mater. Res. Bull., 2015, 64(64), 97-105.

10 Y. Q. Lei, G. H. Wang, S. Y. Song, W. Q. Fan, M. Pang and J. K. Tang, Room temperature, template-free synthesis of BiOI hierarchical structures: visible-light photocatalytic and electrochemical hydrogen storage properties, Dalton Trans., 2010, 39(13), 3273-3278.

11 H. J. Li, Y. Zhou, W. G. Tu, J. H. Ye and Z. G. Zou, State-of-theArt Progress in Diverse Heterostructured Photocatalysts toward Promoting Photocatalytic Performance, Adv. Funct. Mater., 2015, 25(7), 998-1013.

12 S. J. A. Moniz, S. A. Shevlin, D. J. Martin, Z. X. Guo and J. W. Tang, Visible-light driven heterojunction photocatalysts for water splitting-a critical review, Energy Environ. Sci., 2015, 8(3), 731-759.

13 Y. Feng, C. B. Liu, H. N. Che, J. B. Chen, K. Huang, C. Y. Huang and W. D. Shi, The highly improved visible light photocatalytic activity of BiOI through fabricating a novel $\mathrm{p}-\mathrm{n}$ heterojunction $\mathrm{BiOI} / \mathrm{WO}_{3}$ nanocomposite, CrystEngComm, 2016, 18(10), 1790-1799.

14 J. Luo, X. S. Zhou, L. Ma and X. Y. Xu, Enhanced visible-lightdriven photocatalytic activity of $\mathrm{WO}_{3} / \mathrm{BiOI}$ heterojunction photocatalysts, J. Mol. Catal. A: Chem., 2015, 410, 168-176.

15 H. F. Cheng, B. B. Huang, Y. Dai, X. Y. Qin and X. Y. Zhang, One-step synthesis of the nanostructured AgI/BiOI 
composites with highly enhanced visible-light photocatalytic performances, Langmuir, 2010, 26(9), 6618-6624.

16 J. M. Gong, F. Tian, D. H. Peng, A. M. Li and L. Z. Zhang, A highly sensitive photoelectrochemical detection of perfluorooctanic acid with molecularly imprinted polymerfunctionalized nanoarchitectured hybrid of AgI-BiOI composite, Biosens. Bioelectron., 2015, 73, 256-263.

17 J. L. Liang, C. Shan, X. Zhang and M. P. Tong, Bactericidal mechanism of BiOI-AgI under visible light irradiation, Chem. Eng. J., 2015, 279, 277-285.

18 C. C. Zhou, J. Cao, H. L. Lin, B. Y. Xu, B. B. Huang and S. F. Chen, Controllable synthesis and photocatalytic activity of $\mathrm{Ag} / \mathrm{BiOI}$ based on the morphology effect of BiOI substrate, Surf. Coat. Technol., 2015, 272, 213-220.

19 L. F. Zhu, C. He, Y. L. Huang, Z. H. Chen, D. H. Xia, M. H. Su, Y. Xiong, S. Y. Li and D. Shu, Enhanced photocatalytic disinfection of E. Coli 8099 using Ag/BiOI composite under visible light irradiation, Sep. Purif. Technol., 2012, 91(91), 59-66.

20 H. Liu, W. R. Cao, Y. Su, Y. Wang and X. H. Wang, Synthesis characterization and photocatalytic performance of novel visible-light-induced Ag/BiOI, Appl. Catal., B, 2012, 111(2), 271-279.

21 H. L. Lin, Y. J. Zhao, Y. J. Wang, J. Cao and S. F. Chen, Controllable in situ synthesis of $\mathrm{Ag} / \mathrm{BiOI}$ and $\mathrm{Ag} / \mathrm{AgI} / \mathrm{BiOI}$ composites with adjustable visible light photocatalytic performances, Mater. Lett., 2014, 132(10), 141-144.

22 J. Cao, Y. J. Zhao, H. L. Lin, B. Y. Xu and S. F. Chen, Facile synthesis of novel Ag/AgI/BiOI composites with highly enhanced visible light photocatalytic performances, J. Solid State Chem., 2013, 206(10), 38-44.

23 T. T. Li, S. L. Luo and L. X. Yang, Three-dimensional hierarchical Ag/AgI/BiOI microspheres with high visiblelight photocatalytic activity, Mater. Lett., 2013, 109(10), 247-252.

24 W. Qi, X. D. Shi, E. Q. Liu, J. C. Crittenden, X. J. Ma, Y. Zhang

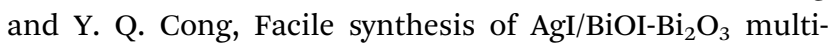
heterojunctions with high visible light activity for $\mathrm{Cr}(\mathrm{VI})$ reduction, J. Hazard. Mater., 2016, 317, 8-16.

25 H. Q. Li, Y. M. Cui and W. S. Hong, High photocatalytic performance of $\mathrm{BiOI} / \mathrm{Bi}_{2} \mathrm{WO}_{6}$ toward toluene and reactive brilliant red, Appl. Surf. Sci., 2013, 264(1), 581-588.

26 Y. Q. Wang, X. F. Cheng, X. T. Meng, H. W. Feng, S. G. Yang and C. Sun, Preparation and characterization of $\mathrm{Ag}_{3} \mathrm{PO}_{4} / \mathrm{BiOI}$ heterostructure photocatalyst with highly visible-lightinduced photocatalytic properties, J. Alloys Compd., 2015, 632, 445-449.

27 T. Yan, M. Sun, H. Y. Liu, T. T. Wu, X. J. Liu, Q. Yan, W. G. Xu and B. Du, Fabrication of hierarchical $\mathrm{BiOI} / \mathrm{Bi}_{2} \quad \mathrm{MoO}_{6}$ heterojunction for degradation of bisphenol $\mathrm{A}$ and dye under visible light irradiation, J. Alloys Compd., 2015, 634(1), 223-231.

28 H. Q. Li, Y. M. Cui, W. S. Hong and B. L. Xu, Enhanced photocatalytic activities of $\mathrm{BiOI} / \mathrm{ZnSn}(\mathrm{OH})_{6}$, composites towards the degradation of phenol and photocatalytic $\mathrm{H}_{2}$ production, Chem. Eng. J., 2013, 228(14), 1110-1120.
29 J. Cao, B. Y. Xu, H. L. Lin, B. D. Luo and S. F. Chen, Chemical etching preparation of $\mathrm{BiOI} / \mathrm{BiOBr}$ heterostructures with enhanced photocatalytic properties for organic dye removal, Chem. Eng. J., 2012, 185-186(1), 91-99.

$30 \mathrm{~K}$. K. Tiong and T. S. Shou, Anisotropic electrolyte electroreflectance study of rhenium-doped $\mathrm{MoS}_{2}$, J. Phys.: Condens. Matter, 2000, 12(23), 5043-5052.

31 H. Wan, L. Xu, W. Q. Huang, J. H. Zhou, C. N. He, X. F. Li, G. F. Huang, P. Peng and Z. G. Zhou, Band structure engineering of monolayer $\mathrm{MoS}_{2}$ : a charge compensated codoping strategy, RSC Adv., 2015, 5(11), 7944-7952.

32 Y. G. Li, Y. L. Li, C. M. Araujo, W. Luo and R. Ahuja, Singlelayer $\mathrm{MoS}_{2}$ as efficient photocatalyst, Catal. Sci. Technol., 2013, 3(9), 2214-2220.

33 W. Y. Gao, M. Q. Wang, C. X. Ran and L. Li, Facile one-pot synthesis of $\mathrm{MoS}_{2}$ quantum dots-graphene-TiO composites for highly enhanced photocatalytic properties, Chem. Commun., 2015, 51(9), 1709-1712.

34 X. W. Li, J. X. Xia, W. S. Zhu, J. Di, B. Wang, S. Yin, Z. G. Chen and H. M. Li, Facile synthesis of few-layered $\mathrm{MoS}_{2}$ modified BiOI with enhanced visible-light photocatalytic activity, Colloids Surf., A, 2016, 511, 1-7.

35 M. J. Islam, D. A. Reddy, N. S. Han, J. Choi, K. J. Song and T. K. Kim, An oxygen-vacancy rich $3 \mathrm{D}$ novel hierarchical $\mathrm{MoS}_{2} / \mathrm{BiOI} / \mathrm{AgI}$ ternary nanocomposite: Enhanced photocatalytic activity through photogenerated electron shuttling in a Z-scheme manner, Phys. Chem. Chem. Phys., 2016, 18(36), 24984-24993.

36 Y. Feng, L. Li, J. Li, J. Wang and L. Liu, Synthesis of mesoporous $\mathrm{BiOBr} 3 \mathrm{D}$ microspheres and their photodecomposition for toluene, J. Hazard. Mater., 2011, 192, 538-544.

37 X. Gao, X. Zhang, Y. Wang, S. Peng, B. Yue and C. Fan, Rapid synthesis of hierarchical BiOCl microspheres for efficient photocatalytic degradation of carbamazepine under simulated solar irradiation, Chem. Eng. J., 2015, 263, 419426.

38 J. Henle, P. Simon, A. Frenzel, S. Scholz and S. Kaskel, Nanosized BiOX ( $\mathrm{X}=\mathrm{Cl}, \mathrm{Br}, \mathrm{I})$ Particles Synthesized in Reverse Microemulsions, Chem. Mater., 2007, 19, 366-373.

39 S. Wu, H. Huang, M. Shang, C. Du, Y. Wu and W. Song, High visible light sensitive $\mathrm{MoS}_{2}$ ultrathin nanosheets for photoelectrochemical biosensing, Biosens. Bioelectron., 2017, 92, 646-653.

40 S. Huang, J. Zhong, J. Li, J. Chen, Z. Xiang, M. Li and Q. Liao, Charge separation and photocatalytic properties of BiOI prepared by ionic liquid-assisted hydrothermal method, Mater. Lett., 2016, 183, 248-250.

41 S. M. Aghdam, M. Haghighi, S. Allahyari and L. Yosefi, Precipitation dispersion of various ratios of $\mathrm{BiOI} / \mathrm{BiOCl}$ nanocomposite over $\mathrm{g}-\mathrm{C}_{3} \mathrm{~N}_{4}$ for promoted visible light nanophotocatalyst used in removal of acid orange 7 from water, J. Photochem. Photobiol., A, 2017, 338, 201-212.

42 H. Wang, L. Ma, M. Gan and T. Zhou, Design and fabrication of macroporous polyaniline nanorods@graphene-like $\mathrm{MoS}_{2}$, nanocomposite with high electrochemical performance for supercapacitors, J. Alloys Compd., 2017, 699, 176-182. 
43 Z. Liu, X. X. Xu, J. Fang, X. M. Zhu, J. H. Chu and B. J. Li, Microemulsion synthesis, characterization of bismuth oxyiodine/titanium dioxide hybrid nanoparticles with outstanding photocatalytic performance under visible light irradiation, Appl. Surf. Sci., 2012, 258(8), 3771-3778.

44 A. C. Mera, Y. Moreno, D. Contreras, D. Escalona, M. F. Melendrez, R. V. Mangalaraja and H. D. Mansilla,
Improvement of the BiOI photocatalytic activity optimizing the solvothermal synthesis, Solid State Sci., 2017, 63, 84-92.

$45 \mathrm{Y}$. Xu and M. A. A. Schoonen, The absolute energy positions of conduction and valence bands of selected semiconducting minerals, Am. Mineral., 2000, 85, 543-556. 